\title{
Technical and Environmental Comparison among Different Municipal Solid Waste Management Scenarios
}

\author{
Deborah Panepinto *(D) and Mariachiara Zanetti \\ Department of Engineering for Environment, Land and Infrastructures (DIATI), Politecnico di Torino, \\ 10129 Torino, Italy; mariachiara.zanetti@polito.it \\ * Correspondence: deborah.panepinto@polito.it; Tel.: +39-011-090-7660
}

Citation: Panepinto, D.; Zanetti, M.

Technical and Environmental Comparison among Different Municipal Solid Waste Management Scenarios. Sustainability 2021, 13, 3167. https://doi.org/10.3390/ su13063167

Academic Editor: Dimitrios Komilis

Received: 1 February 2021

Accepted: 10 March 2021

Published: 13 March 2021

Publisher's Note: MDPI stays neutral with regard to jurisdictional claims in published maps and institutional affiliations.

Copyright: (c) 2021 by the authors. Licensee MDPI, Basel, Switzerland. This article is an open access article distributed under the terms and conditions of the Creative Commons Attribution (CC BY) license (https:// creativecommons.org/licenses/by/ $4.0 /)$.

\begin{abstract}
In order to determine the optimal final destination of municipal solid waste, it is necessary to consider both monetary costs and environmental externalities, as well as the local availability of waste-processing industrial infrastructure. The paper examines the results obtained from a technical, economic, and environmental comparison between different scenarios for waste management: in particular, the solutions of gasification and pyrolysis were studied and, afterwards, were compared with direct combustion in incineration plant (from the point of view of the thermal treatment) and final disposal in landfill. In order to perform this analysis, 19 plants operating on full scale were analyzed. The comparison took into account environmental, energy, and economic aspects. From the environmental and energetical point of view, the tool of mass and energy balance was used to address some key environmental aspects. In particular, some indexes were defined in order to perform a comparison among the different analyzed solutions. As concerns the economic point of view, conventional economic criteria were considered. The analysis showed advantages for the examined thermal treatment solutions. The comparison methodology that has been defined can establish a more general useful approach in order to help the definition of the best solution for waste management planning.
\end{abstract}

Keywords: municipal solid waste (MSW) disposal; thermal treatment; landfill; environmental aspects; economic aspects

\section{Introduction}

In order to determine the optimal final destination of municipal solid waste, it is necessary to consider not only the monetary costs but also the environmental externalities, such as carbon balance and greenhouse gas (GHG) production [1]. Furthermore, for a given location, the availability of waste-processing industrial infrastructures (separation plants, waste to energy (WtE) systems, final landfills, other innovative solutions) or the cost of their construction must also be taken into account. While upgrading to the best available technology (BAT) might lead to a substantial reduction in the emissions of a particular pollutant, this high improvement could also increase the level of released carbon dioxide. In any case, in order to obtain a complete picture of the waste-processing system, the total energy expenditure of that system must be considered $[2,3]$.

Currently (early 2010), the primary method adopted for municipal solid waste treatment is waste separation in the collection process, with the goals of reuse and production of recycled materials. In northern Italy, for example, separation levels have reached about $50 \%$ b.w., with values higher than $70 \%$ in some areas [4]. Downstream of this collection scheme, however, there is a significant flow of undifferentiated waste, to which the discards from the valorization process for the reusable waste must be added, i.e., suitable solutions must be found for the disposal of these additional flows too [5]. Moreover, these flows, which involve a high percentage of gross waste production (from a minimum of 55-60\% to a maximum of $90 \%$ ), contain a much lower fraction of reusable materials (metal, glass, 
organic material) and consist of a combustible fraction, a residual wet organic fraction, and a substantially inert mineral fraction. Considering this composition, along with the interest in the production of electricity and thermoelectric energy from non-fossil sources, there is a potential energy recovery from this fraction with the double aim of residual waste disposal and, at the same time, of producing electricity and thermal energy in an environmentally compatible way [6,7].

It is generally agreed that there are two alternative methods of achieving this recovery: energetic valorization of the undifferentiated flow (through either direct combustion in incinerators or treatment in plants using innovative technologies such as gasification, pyrolysis, or in the future, plasma technology) or mechanical separation systems downstream of the selective collection. These mechanical systems separate the waste into three fractions: a fuel fraction (known as refuse derived fuel (RDF), which can be used in specific dedicated plants or introduced into the general fuel market), a wet fraction (for which, with the possibility of biological stabilization in anaerobic digestion plants, there is also a prospect for indirect energy valorization), and a mineral fraction, for which there is currently no option except disposal in a landfill. Of the two above-mentioned alternatives, the first one is certainly the most widely used today, both in Italy and in most technologically advanced areas of Europe (this is certainly true for countries such as Italy, French, Germany, and also England and Norway) [8,9]) for reasons of simplicity, economic convenience, and the elimination of the problems of secondary flows other than ash. The second alternative, however, is receiving increasing attention today as it is considered more environmentally sound, requires less additional infrastructure, and is more compatible with other plants already operating.

In the present work, different technologies for final waste disposal (thermal treatment such as pyrolysis / gasification and incineration and landfill) are evaluated with the aim of the valorization of a particular local waste stream. The purpose of the study is to develop an evaluation methodology that can be applied both to specific local conditions and as a general approach in order to develop a strategy for choosing an optimal method for waste management.

From a general viewpoint, the novelty of the work is the definition of synthetic indexes, through which it is possible to evaluate different waste management scenarios from a technological and environmental point of view.

\section{Methodology}

\subsection{General Overview}

As discussed above, in this paper, several technological solutions for the satisfactory disposal of municipal solid wastes were examined. The primary consideration for selecting among the various treatment scenarios is the avoidance of unacceptable impacts on the local area. This result can only be obtained by implementing the BAT [10], which limits the amount of released pollutants while remaining practical and cost-effective. In this context, it is necessary to highlight that the BAT application is a condition necessary but not sufficient in order to avoid the impact on local scale. Several different approaches were considered for determining this optimal solution. One option was to use a multicriteria analysis [11] that identifies appropriate indicators for the benefits and criticalities of the proposed solution and assigns to each indicator an appropriate weight, which is then inserted into a complex algorithm. Although the basic concept of this approach is sound, the development of the reference matrix is a subjective and questionable process, preventing the final results from being truly objective and unambiguous. Other proposed approaches could determine either the most cost-effective solution or the one with the least environmental impact. What is needed, however, is an objective and meaningful approach that can combine these two aspects and evaluate the total burden on the community, in other words, the total social cost for waste disposal, including the value that could be realized by using the waste for energy production $[12,13]$. The total social cost is the sum of the industrial and environmental costs, the latter being essentially the pollutant load that a 
solution imposes on the territory where the pollutant will be discharged and, by extension, on the downstream environment $[2,3]$.

An early paper [14] investigated the relative importance of several different types of impact. A follow-up study [15] took into account the numerical results reported in that paper and attempted to compare these impacts based on order of magnitude. The major conclusion from these studies was that, in the evaluation of the externalities, only the external cost of $\mathrm{CO}_{2}$ emissions can be considered significant. When considering the acceptability of this important simplification, it should be clearly observed that not only is this type of impact the most significant (and this consideration certainly minimizes the affected approximation), it is also the most reliably known on the basis of mass and energy balance, especially compared to other types of impact, for which different technological structures can lead to large variations in the emission levels. Hence the results obtained from this evaluation can be considered significant and acceptable. In this paper, different thermal treatment solutions, namely, direct combustion in incineration plant, gasification, and pyrolysis, have been compared. The gasification and pyrolysis treatment of solid materials are not a new concept. Both these technologies have been extensively used to produce fuels, such as coke and town gas, for hundreds of years. Large scale gasification units used by the petrochemical and power industries have several hundred installations worldwide. The characteristics of these systems typically are very high temperatures $\left(1100{ }^{\circ} \mathrm{C}\right.$ and higher), short residence time and extremely rapid conversion of material in the gasification zone, and very careful feedstock preparation by means of crushing and sieving the feed with a controlled moisture content. It is evident that the characteristics of municipal solid waste (MSW) (inconstant in size and moisture content and highly variable in heat calorific value) do not easily fit these demands. Heat and mass transfer dynamics between a selected feed as automotive shredder residues (ASR), plastic, biomass, or MSW are very different [16-19] and feedstock preparation could exceed the economic parameters $[20,21]$. Today, the main difficulties in applying the principles of gasification to MSW seem to be solved, and gasification could be a reliable solution for waste disposal: there are in fact as many as 100 plants around the world that use gasification systems to process MSW. One of the potential benefits of gasification is that the syngas can be used not only to produce steam, which can be used to generate electricity by a steam turbine, but also to feed a dedicated gas engine or a gas turbine; in addition to using the syngas to produce energy, it can also be used as a chemical feedstock.

This paper investigated several facilities for MSW gasification all over the world in order to evaluate the environmental and energetic issues spotlighting the advantages and disadvantages of this technology, the development opportunities, and the open problems. These facilities have been compared with the direct combustion facilities and finally with the landfill option.

\subsection{Indexes Used for the Evaluation}

As previously indicated in this paper, different thermal treatment solutions (in particular, innovative solutions, such as gasification and pyrolysis, and also traditional solutions, such as direct combustion in incineration plant) have been compared, using four different indexes and in particular:

- the first index concerns the ratio between the produced energy and the treated wastes amount $\left(\mathrm{kWh} / \mathrm{t}_{\mathrm{MSW}}\right)$;

- the second index concerns the ratio between pollutant concentrations emitted from the plant and the energy produced from the same plant. The pollutant parameters considered are $\mathrm{NO}_{\mathrm{x}}$ and $\mathrm{PM}\left(\mathrm{mg} / \mathrm{Nm}^{3}\right.$ pollutted $\left./ \mathrm{kWh}\right)$;

- the third index concerns the ratio between pollutant concentrations emitted from the plant and the treated wastes. Additionally, in this case, the considered pollutant parameters are $\mathrm{NO}_{\mathrm{x}}$ and $\mathrm{PM}\left(\mathrm{mg} / \mathrm{Nm}^{3}\right.$ pollutted $\left./ \mathrm{t}_{\mathrm{MSW}}\right)$;

- the fourth index concerns the ratio between the total amount of $\mathrm{CO}_{2 \mathrm{e}}$ produced from the plant and the total treated wastes $\left(\mathrm{t}_{\mathrm{CO} 2 \mathrm{e}} / \mathrm{t}_{\mathrm{MSW}}\right)$. 
The last index, fourth index, concerning the pollutant carbon dioxide $\left(t_{\mathrm{CO} 2} / \mathrm{t}_{\mathrm{MSW}}\right)$, has been also used in order to perform the comparison between the thermal treatment solutions and the solution of the waste final disposal in landfill. The developed indexes allow us to have a general framework of the analyzed technology; in fact; they depend certainly on the composition of the MSW in input but also on the adopted technology for the energy revenue and also on the employed flue gas depuration line.

In particular, the composition of waste is a very important parameter for the operation of each plant: the flue gas depuration line to be adopted and the amount of energy recovery also depend on it.

\subsection{Analyzed Plants}

In the following Tables (Tables 1 and 2), the analyzed plants, with the main features, are reported. In particular, 11 gasification and pyrolysis plants and five incineration plants have been analyzed. All the analyzed plants were operating on full scale. The considered plant suppliers/owner were consolidated (in this specific treatment field) with a lot of reference plants.

Table 1. List of the analyzed plants with the main features.

\begin{tabular}{|c|c|c|c|c|}
\hline Plant Supplier/Plant Owner & Plant Examined & Thermal Technology & Potentiality $[t / y]$ & Availability $[\mathrm{h} / \mathrm{y}$ or $\mathrm{d} / \mathrm{y}]$ \\
\hline Ebara & Tokyo (Japan) & Gasification & $34,000-180,000$ & $7200 \mathrm{~h} / \mathrm{y}$ \\
\hline Nippon Steel & Shinmoji Kitakyushu (Japan) & Gasification & $30,000-230,000$ & $7500 \mathrm{~h} / \mathrm{y}$ \\
\hline Mitsubishi & Kushiro (Japan) & Pyrolysis/Gasification & - & $320 \mathrm{~d} / \mathrm{y}$ \\
\hline JFE Thermoselect & Chiba Recycling Center (Japan) & Pyrolysis/Gasification & $30,000-200,000$ & $7500 \mathrm{~h} / \mathrm{y}$ \\
\hline Bestrade P2P & UK & Pyrolysis & Around 100,000 & \\
\hline Printer & Terni (Italy) & Pyrolysis & 32,000 & $320 \mathrm{~d} / \mathrm{y}$ \\
\hline Sipsa Ecologica spa & Torregrande (Italy) & Pyrolysis & 10,000 & $320 \mathrm{~d} / \mathrm{y}$ \\
\hline Techrade & Hamm (Germany) & Pyrolysis & $40,000-110,000$ & $7500 \mathrm{~h} / \mathrm{y}$ \\
\hline Energos & Sarpsborg II (Norway) & Gasification & $10,000-75,000$ & $7800 \mathrm{~h} / \mathrm{y}$ \\
\hline Metso Lahti Energia & Kymijarvi II (Finland) & Gasification & $250,000-300,000$ & $7500 \mathrm{~h} / \mathrm{y}$ \\
\hline Compact Power & Avonmouth (UK) & Pyrolysis/gasification & 8000 & - \\
\hline CNIM & Turin (Italy) & Incineration & 421,000 & $7800 \mathrm{~h} / \mathrm{y}$ \\
\hline $\mathrm{A} 2 \mathrm{~A}$ & Brescia (Italy) & Incineration & 880,000 & $7800 \mathrm{~h} / \mathrm{y}$ \\
\hline $\mathrm{A} 2 \mathrm{~A}$ & Milano-Silla2 (Italy) & Incineration & 480,000 & $7800 \mathrm{~h} / \mathrm{y}$ \\
\hline FEA (Hera Ambiente) & Granarolo dell'Emilia (Italy) & Incineration & 218,000 & $7800 \mathrm{~h} / \mathrm{y}$ \\
\hline $\mathrm{A} 2 \mathrm{~A}$ & Acerra (Italy) & Incineration & 600,000 & $7800 \mathrm{~h} / \mathrm{y}$ \\
\hline
\end{tabular}

Table 2. List of the analyzed plants with the indication of the adopted flue gas depuration line.

\begin{tabular}{lll}
\hline Plant Supplier/Plant Owner & Plant Examined & Flue Gas Depuration Line \\
\hline Ebara & Tokyo (Japan) & Bag Filter-Wet Scrubber-SCR \\
Nippon Steel & Shinmoji Kitakyushu (Japan) & Bag Filter-Wet Scrubber-SCR \\
Mitsubishi & Kushiro (Japan) & Bag Filter-SCR \\
JFE Thermoselect & Chiba Recycling Center (Japan) & Dry Scrubber-Wet Scrubber-SCR \\
Bestrade P2P & UK & Bag Filter-Dry Scrubber-SCR \\
Printer & Terni (Italy) & SNCR-Cyclone-Dry Scrubber-Bag Filter \\
Sipsa Ecologica spa & Torregrande (Italy) & Cyclone-Dry Scrubber-Bag Filter \\
Techrade & Hamm (Germany) & Dry Scrubber-Bag Filter-SCR \\
Energos & Sarpsborg II (Norway) & Dry Scrubber-Bag Filter-Selective No Catalytic Removal (SNCR) \\
Metso Lahti Energia & Kymijarvi II (Finland) & Ceramic Filter-Dry Scrubber-SCR \\
Compact Power & Avonmouth (UK) & Bag Filter-Dry Scrubber-SCR \\
CNIM & Turin (Italy) & Electrofilter-Dry Scrubber-Bag Filter-SCR \\
A2A & Brescia (Italy) & Electrofilter-Dry Scrubber-Bag Filter-SCR \\
A2A & Milano-Silla2 (Italy) & Electrofilter-Dry Scrubber-Bag Filter-SCR \\
FEA (Hera Ambiente) & Granarolo dell'Emilia (Italy) & Cyclone-Wet Scrubber-Bag Filter-SCR \\
A2A & Acerra (Italy) & Semi Dry Scrubber-Bag Filter-Dry Scrubber-Bag Filter-SCR \\
\hline
\end{tabular}

In order to perform the comparison and, therefore, to define the specific indexes, the data supplied by the plant manager were used. The last plant that was analyzed, as already reported, was a landfill plant. In order to perform the comparison, some literature data [22] were used. The performed analysis is obviously affected by some uncertainty, in particular, 
due to the different quality of the waste input and to the scale effect. However, this is an attempt to develop a standard methodology (based on the analyzed indexes) that can be applied to different cases.

\section{Results}

In the following text, the main results concerning the environmental and economic aspects are reported.

\subsection{Energetical and Environmental Results}

As already reported, in order to perform the comparison, some indexes were calculated and evaluated. The first index (called index A) considered refers to the amount of energy (electric or thermal and electric energy as a function of the energy adopted configuration) produced from the different plants (innovative and traditional). The data for the evaluation are supplied from the plant's owner. In Table 3, the obtained results are reported (split in two different indexes, one concerning the thermal energy- $\mathrm{MWh}_{\mathrm{th}} / \mathrm{t}_{\mathrm{MSW}}$, and one concerning the electric energy $-\mathrm{MWh}_{\mathrm{e}} / \mathrm{t}_{\mathrm{MSW}}$ ).

Table 3. Results concerning the energetical index.

\begin{tabular}{ccc}
\hline Plant Supplier/Plant Owner & Index A $\left[\mathbf{M W h} \mathbf{h}_{\mathbf{t h}} / \mathbf{t}_{\mathbf{M S W}}\right]$ & Index $\mathbf{A}\left[\mathbf{M W h}_{\mathbf{e}} / \mathbf{t}_{\mathbf{M S W}}\right]$ \\
\hline Ebara & 0.39 & 0.20 \\
Nippon Steel & 0.30 & 0.15 \\
Mitsubishi & - & 0.11 \\
JFE Thermoselect & 0.06 & 0.07 \\
Bestrade P2P & 4.18 & 3.36 \\
Printer & - & 0.95 \\
Sipsa Ecologica spa & 2.59 & 0.67 \\
Techrade & - & 1.40 \\
Energos & 1.3 & 0.7 \\
Metso Lahti Energia & 2.4 & 1.2 \\
Compact Power & 0.21 & 0.10 \\
CNIM & - & 2.04 \\
A2A_Brescia & 1.01 & 0.88 \\
A2A_Milano & 0.40 & 0.75 \\
FEA_Granarolo & 0.21 & 0.64 \\
A2A_Acerra & - & 0.95 \\
\hline
\end{tabular}

By analyzing the results reported in Table 3, it is possible to note that the plants with the higher indexes are Bestrade P2P, Sipsa Ecologica, Metso Lahti Energia, and CNIM. The reason is due especially to the high specific heating value of the waste input to these specific plants. In this sense, it is important to note that the waste input to the Bestrade P2P include MSW and also residual mix plastic materials (this is the reason for the higher heating value for this waste stream). From the environmental point of view, two different indexes are considered. The first one concerns the pollutant concentration in output from the chimney (thus after a flue gas depuration treatment, called index B and C); the second one, in order to supply some indications about the GHG impact, concerns the amount of $\mathrm{CO}_{2 \mathrm{e}}$ generated and emitted (called index D). From the point of view of the first index, two different pollutant parameters are considered: $\mathrm{NO}_{x}$ and $\mathrm{PM}$. The considered parameters are the main problematic pollutants for these kinds of plants. These concentrations were referred to as the amount of treated wastes (called index B) and as the amount of produced energy (called index C). Additionally, in this case the data are supplied from the plant's owner. In Tables 4 and 5, the two indexes $B$ and $C$ have been reported. 
Table 4. Results concerning the environmental indexes (referred to as the amount of treated wastes).

\begin{tabular}{ccc}
\hline Plant Supplier/Plant Owner & Index B $\left[\mathbf{c}_{\mathbf{N O x}} / \mathbf{k g}_{\mathbf{M S W}}\right]^{*}$ & ${\text { Index B }\left[\mathbf{c}_{\mathbf{P M}} / \mathbf{k g} \mathbf{M S W}\right]}^{*}$ \\
\hline Ebara & $5.40 \times 10^{-5}$ & $1.82 \times 10^{-6}$ \\
Nippon Steel & $4.57 \times 10^{-5}$ & $1.53 \times 10^{-6}$ \\
Mitsubishi & $1.27 \times 10^{-4}$ & $3.33 \times 10^{-6}$ \\
JFE Thermoselect & $5.38 \times 10^{-5}$ & $3.77 \times 10^{-7}$ \\
Bestrade P2P & $3.29 \times 10^{-3}$ & $4.16 \times 10^{-4}$ \\
Printer & $1.50 \times 10^{-3}$ & $5.20 \times 10^{-5}$ \\
Sipsa Ecologica spa & $6.40 \times 10^{-3}$ & $3.20 \times 10^{-4}$ \\
Techrade & $6.40 \times 10^{-4}$ & $5.76 \times 10^{-6}$ \\
Energos & $3.13 \times 10^{-4}$ & $1.25 \times 10^{-6}$ \\
Metso Lahti Energia & $2.05 \times 10^{-4}$ & $2.56 \times 10^{-6}$ \\
Compact Power & $3.95 \times 10^{-4}$ & $2.13 \times 10^{-6}$ \\
CNIM & $1.30 \times 10^{-7}$ & $9.26 \times 10^{-9}$ \\
A2A_Brescia & $1.26 \times 10^{-6}$ & $3.59 \times 10^{-9}$ \\
A2A_Milano & $1.12 \times 10^{-6}$ & $3.08 \times 10^{-9}$ \\
FEA_Granarolo & $6.12 \times 10^{-6}$ & $5.13 \times 10^{-8}$ \\
A2A_Acerra & $1.40 \times 10^{-6}$ & $8.60 \times 10^{-9}$
\end{tabular}

${ }^{*} \mathrm{C}=$ concentration.

Table 5. Results concerning the environmental indexes (referred to the amount of produced energy).

\begin{tabular}{ccc}
\hline Plant Supplier/Plant Owner & Index $\mathbf{C}\left[\mathbf{c}_{\mathbf{N O x}} / \mathbf{k W h}\right]$ & Index $\mathbf{C}\left[\mathbf{c}_{\mathbf{P M}} / \mathbf{k W h}\right]$ \\
\hline Ebara & $3.07 \times 10^{-7}$ & $1.04 \times 10^{-8}$ \\
Nippon Steel & $3.70 \times 10^{-7}$ & $1.00 \times 10^{-8}$ \\
Mitsubishi & $3.55 \times 10^{-6}$ & $9.30 \times 10^{-8}$ \\
JFE Thermoselect & $1.28 \times 10^{-6}$ & $8.99 \times 10^{-9}$ \\
Bestrade P2P & $1.30 \times 10^{-6}$ & $1.65 \times 10^{-7}$ \\
Printer & $4.93 \times 10^{-6}$ & $1.71 \times 10^{-7}$ \\
Sipsa Ecologica spa & $6.13 \times 10^{-6}$ & $3.07 \times 10^{-7}$ \\
Techrade & $1.43 \times 10^{-6}$ & $1.29 \times 10^{-8}$ \\
Energos & $4.73 \times 10^{-7}$ & $1.89 \times 10^{-9}$ \\
Metso Lahti Energia & $1.78 \times 10^{-7}$ & $2.22 \times 10^{-9}$ \\
Compact Power & $3.98 \times 10^{-6}$ & $1.08 \times 10^{-6}$ \\
CNIM & $6.44 \times 10^{-8}$ & $4.60 \times 10^{-9}$ \\
A2A_Brescia & $2.16 \times 10^{-6}$ & $6.01 \times 10^{-11}$ \\
A2A_Milano & $3.24 \times 10^{-7}$ & $8.54 \times 10^{-10}$ \\
FEA_Granarolo & $2.30 \times 10^{-6}$ & $1.93 \times 10^{-8}$ \\
A2A_Acerra & $4.65 \times 10^{-7}$ & $2.75 \times 10^{-9}$ \\
\hline
\end{tabular}

By analyzing the results reported in Tables 4 and 5 , it is possible to note that, from the environmental point of view, the best solution is direct combustion in an incineration plant. Finally, the last evaluated index concerns the amount of $\mathrm{CO}_{2 \mathrm{e}}$ produced from the plants. In order to calculate the amount of produced carbon dioxide, it has been assumed that all the carbon contained in the input waste stream would become carbon dioxide. This amount has been referred to as the amount of treated wastes (index D- $\mathrm{t}_{\mathrm{CO} 2} / \mathrm{t}_{\mathrm{MSW}}$ ) and depends in particular on the elemental composition of the material being input to the plant. Table 6 reports the obtained results.

By analyzing the results reported in Table 6, it is possible to note that the situation is quite similar considering both innovative or traditional thermal treatment solutions. From the point of view of the Bestrade P2P, the high index is due to the large amount of plastic present in the treated waste. As already said for this index (index D), a comparison was also performed with the solution of the waste final disposal in landfill using data present in literature. For determining the avoided emissions from landfill, instead of using life cycle assessment (LCA) and modeling software such as GaBi [23] or SimaPro, we considered only the stoichiometry of conversion [1]: it can be established that for $100 \mathrm{~g}$ of MSW, there is 
a generation of $29.78 \mathrm{~g}$ of $\mathrm{CH}_{4}$ and $58.91 \mathrm{~g}$ of $\mathrm{CO}_{2}$. These amounts, as well as the following ones, were obtained using the mass balance method.

Table 6. Results concerning the carbon dioxide index.

\begin{tabular}{cc}
\hline Plant Supplier/Plant Owner & Index D $\left[\mathbf{t}_{\mathbf{C O} 2 \mathbf{e}} / \mathbf{t}_{\mathbf{M S W}}\right]$ \\
\hline Ebara & 1.65 \\
Nippon Steel & 1.47 \\
Mitsubishi & 0.73 \\
JFE Thermoselect & 1.83 \\
Bestrade P2P & 3.15 \\
Printer & 1.47 \\
Sipsa Ecologica spa & 2.20 \\
Techrade & 1.47 \\
Energos & 1.47 \\
Metso Lahti Energia & 1.65 \\
Compact Power & 2.20 \\
CNIM & 1.56 \\
A2A_Brescia & 0.99 \\
A2A_Milano & 2.52 \\
FEA_Granarolo & 2.27 \\
A2A_Acerra & 1.83 \\
Landfill 1 (Turin Landfill) & 3.27 \\
Landfill 2 & 3.15 \\
Landfill 3 & 3.03 \\
\hline
\end{tabular}

By considering [24] an efficiency of 0.55 in biogas collection, we have:

- Emissions avoided by capturing biogas: a ratio of about 0.55 ;

- The biogas not captured (a ratio of about 0.45 ) is released as diffusive emissions.

In this last case, the index is equal to $3.27 \mathrm{t}_{\mathrm{CO} e} / \mathrm{t}_{\mathrm{MSW}}$ [1] for Landfill 1 (this value is related to the MSW landfill present in the province of Turin), 3.15 for Landfill 2 and 3.03 for Landfill 3 (for all three considered landfills, a ratio of capturing biogas equal to 0.55 was considered). Therefore, considering these last results, it is possible to conclude that, from the environmental point of view (considering the $\mathrm{CO}_{2 \mathrm{e}}$ emission), the thermal solution (pyrolysis/gasification and incineration) is better than the landfill solution.

\subsection{Economic Results}

From the point of view of the economic aspect, in Table 7, some indications concerning the investment and management costs for the analyzed thermal treatment plants are reported.

Obviously, the costs depend on the plant size. By analyzing the literature [24,25], it is possible to note that the costs reported in Table 7 fall down into the literature range (Table 8 and Figure 1).

\subsection{Discussion}

By analyzing the obtained results, it is possible to note that the solution of thermal treatment is better in comparison to the solution of the final disposal in landfill. This result is in agreement with the waste hierarchy [26], which foresees the landfill solution in last position. By analyzing all the thermal treatment processes, direct combustion seems to be the better solution, both from the environmental and economic point of view. More generally, from the performed analysis, the following aspects have emerged:

- from the environmental point of view, the elaborated indexes highlight a compatibility of the thermal treatment solutions. In particular, this result has emerged when analyzing index B. In this sense, it is possible to note that the obtained results are closely connected with the adopted flue gas depuration line. These clean systems, according to the BAT [27], are always more performant. The flue gas depuration line, 
of all the considered plants, foresees three main parts: a section for the dust abatement (in general electrofilter and/or bag filter), a section for the acid gas abatement (in general wet or dry scrubber with injection of specific reagent), and a section for the $\mathrm{NO}_{\mathrm{x}}$ abatement (in general a selective catalytic removal system);

- from the energetic revenue point of view, all the analyzed plants present values of the corresponding indexes that highlight a great efficiency. The Metso Lahti Energia plant is certainly interesting. The energy revenue operating from this specific plant is very high, taking into account, in particular, the adopted specific syngas depuration system (ceramic filter) that foresees to eliminate the major part of the present TAR, thus, obtaining a high energetic revenue;

- for all the analyzed technologies, the $\mathrm{CO}_{2 \mathrm{e}}$ emission problem exists (it is also important to note that in Europe, MSW is approximately $50 \%$ biogenic-i.e., originated from renewable biomass. This means that approximately $50 \%$ of the $\mathrm{CO}_{2}$ emissions have a zero net impact on the $\mathrm{CO}_{2}$ balance in the atmosphere so the problem is for the remaining 50\%). Actually, technologies for $\mathrm{CO}_{2}$ reduction (such as amine-based absorption pants) are not very widespread for two main reasons: both capex and opex are high, and the $\mathrm{CO}_{2}$ pollutant parameters are not regulated. In this way, all the carbon present in the input waste to the plant becomes carbon dioxidein, the flue gas coming out of the chimney. This is a great problem because carbon dioxide is a GHG, and it is one of the major ones responsible for climate change. Further studies in order to find a solution to this problem are certainly necessary.

Table 7. Economical indications.

\begin{tabular}{ccc}
\hline Plant Supplier/Plant Owner & Investment Cost [M€] & Management Cost \\
\hline Ebara & - & - \\
Nippon Steel & $200(870 € / \mathrm{t} / \mathrm{y})$ & - \\
Mitsubishi & - & - \\
JFE Thermoselect & - & $200 € / \mathrm{t}$ \\
Bestrade P2P & 7 (for unit of $25 \mathrm{t} / \mathrm{d})(1750 € / \mathrm{t} / \mathrm{y})$ & $0.78 \mathrm{M} / \mathrm{y}$ \\
Printer & $11.5(360 € / \mathrm{t} / \mathrm{y})$ & - \\
Sipsa Ecologica spa & - & - \\
Techrade & - & $1 \mathrm{M} € / \mathrm{y}$ \\
Energos & $50(666 € / \mathrm{t} / \mathrm{y})$ & - \\
Metso Lahti Energia & $160(533 € / \mathrm{t} / \mathrm{y})$ & - \\
Compact Power & $9.6(1.200 € / \mathrm{t} / \mathrm{y})$ & $30 \mathrm{M} € / \mathrm{y}$ \\
CNIM & $310(736 € / \mathrm{t} / \mathrm{y})$ & $55 \mathrm{M} € / \mathrm{y}$ \\
A2A_Brescia & - & - \\
A2A_Milano & - & $34 \mathrm{M} € / \mathrm{y}$ \\
FEA_Granarolo & - & - \\
A2A_Acerra & $332(553 € / \mathrm{t} / \mathrm{y})$ &
\end{tabular}

Table 8. Literature economical indications [24].

\begin{tabular}{cc}
\hline Plant Size [t/y] & Investment Cost [M€] \\
\hline 50,000 & $27-38$ \\
$100,000-115,000$ & $40-65$ \\
150,000 & $50-95$ \\
$170,000-200,000$ & $65-110$ \\
\hline
\end{tabular}




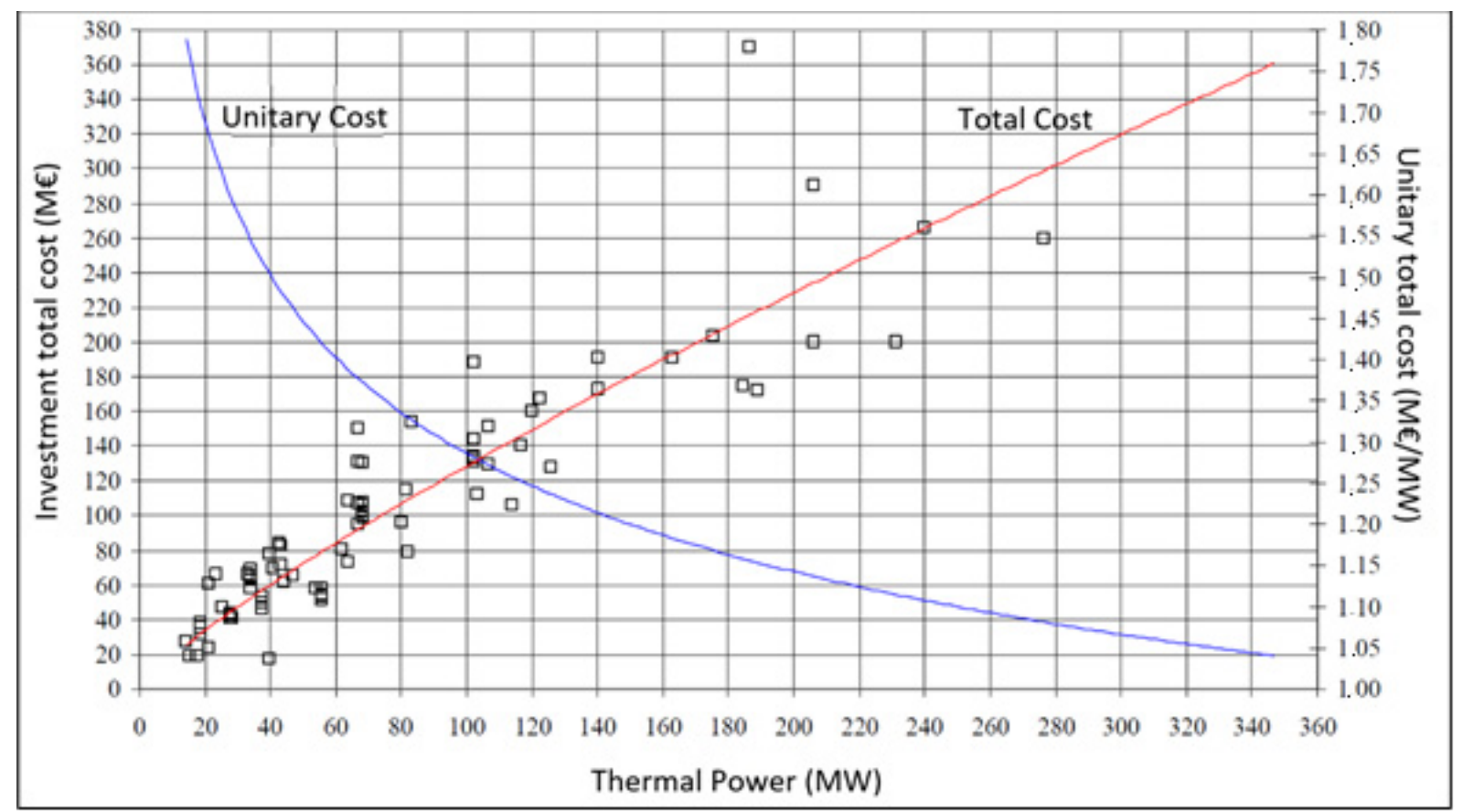

Figure 1. Investment costs as a function of the thermal power [24].

\section{Conclusions}

The paper examines the results obtained from the comparison between different scenarios for waste management: in particular the solutions of gasification and pyrolysis, the direct combustion in incineration plants, and the final disposal in landfill were analyzed. In order to perform this analysis, 19 plants (thermal treatment and landfill) operating on full scale were analyzed. From the environmental and energetical point of view, the tool of mass and energy balance has been used to address some key environmental aspects and the global acceptance of these scenarios. In particular, some indexes were defined in order to perform the comparison of the different analyzed solutions. As it concerns the economic point of view, conventional economic criteria have been considered. The results of the performed analysis show from the environmental and energetical point of view a convenience for the thermal treatment solutions (both considering incineration or gasification solutions). In particular, the first analyzed index (index A), referring to the amount of produced energy, shows a convenience for the plants of the Bestrade P2P, Sipsa Ecologica, Metso Lahti Energia (gasification plants), and CNIM (incineration plant). The reason is especially due to the high specific heating value of the specific treated wastes. From the point of view of the second and third indexes (indexes $B$ and $C$ referring to the ratio between emitted pollutant parameters and the amount of treated wastes or the amount of produced energy), the best solution is direct combustion in an incineration plant (in this case the indexes depend, in particular, on the adopted flue gas depuration line). By analyzing the results concerning the fourth index (index D) regarding the amount of emitted carbon dioxide, it is possible to note that the results for innovative and traditional thermal treatment solutions are quite similar and generally better in comparison to the landfill solution. From the economic point of view, the obtained results show that the situation, with some exceptions, is quite similar for both innovative and traditional thermal treatment solutions. Obviously, the costs depend on the plant size.

In conclusion, the specific obtained results depend mostly on the waste composition, the flue gas treatment, and the heat and power delivery requirements, but the comparison methodology that has been defined can establish a more general useful approach in order to help define the best solution for waste management planning. 
Author Contributions: Conceptualization, All; methodology, All; software, All; validation, All; formal analysis, All; investigation, All; resources, All; data curation, All; writing-original draft preparation, All; writing-review and editing, All; visualization, All; supervision, All; project administration, All; funding acquisition, All. All authors have read and agreed to the published version of the manuscript.

Funding: This research received no external funding.

Institutional Review Board Statement: Not applicable.

Informed Consent Statement: Not applicable.

Data Availability Statement: Not applicable.

Conflicts of Interest: The authors declare no conflict of interest.

\section{References}

1. Panepinto, D.; Genon, G. Carbon dioxide balance and cost analysis for different solid waste management scenarios. Waste Biomass Valorization 2012, 3, 249-257. [CrossRef]

2. Wittmaier, M.; Langer, S.; Sawilla, B. Possibilities and limitationsof life cycle assessment (LCA) in the development of waste utilization systems—applied examples for a region in Northern Germany. Waste Manag. 2009, 29, 1732-1738. [CrossRef] [PubMed]

3. Cherubini, F.; Bargigli, S.; Ulgiati, S. Life cycle assessment (LCA) of waste management strategies: Landfilling, sorting plant and incineration. Energy 2009, 34, 2116-2123. [CrossRef]

4. ISPRA (Istituto Superiore per la Protezione e la Ricerca Ambientale). Rapporto Rifiuti. Available online: http://www.apat.gov.it/ site/it-IT / APAT/Pubblicazioni/Rapporto_rifiuti/Documento/rapporto_rfi08.html\#Sommario (accessed on 28 February 2021).

5. Liu, Y.; Xing, P.; Liu, J. Environmental performance evaluation of different municipal solid waste management scenarios in China. Resour. Conserv. Recycl. 2017, 125, 98-106. [CrossRef]

6. Arena, U. Process and technological aspects of municipal solid waste gasification. A review. Waste Manag. 2012, 32, 625-639. [CrossRef] [PubMed]

7. Shen, C.; Aihong, M.; Yanqiu, L.; Hui, Z.; Qinghai, L.; Yanguo, Z. TGA pyrolysis and gasification of combustible municipal solid waste. J. Energy Inst. 2015, 88, 332-343.

8. Gormley, T.P. New Landfill Ban on Biodegradable Easte. Available online: https://www.internationallawoffice.com/Newsletters/ Environment-Climate-Change/Norway / Arntzen-de-Besche-Advokatfirma-AS/New-Landfill-Ban-on-Biodegradable-Waste (accessed on 3 March 2021).

9. Confederation of European Waste to Energy Plants (CEWEP). Latest Eurostat Figures: Municipla Waste Treatment 2018. Available online: https: / / www.cewep.eu/municipal-waste-treatment-2018 (accessed on 3 March 2021).

10. IPPC (Integrated Pollution Prevention and Control). European Commission, Reference Document on the Best Available Techniques for Waste Incineration. 2006. Available online: http:/ /www.prtr-es.es/data/images/BREF\%20Tratamiento $\% 20 \mathrm{de} \% 20$ Residuos-21891D712A33A259.pdf (accessed on 3 March 2021).

11. Powell, J.C. The evaluation of waste management options. Waste Manag. Res. 1996, 14, 515-526. [CrossRef]

12. Huhtala, A. How much do money, inconvenience and pollutant matter? Analysis household demand for large-Scale recycling and incineration. J. Environ. Manag. 1999, 55, 27-38. [CrossRef]

13. Mirandce, M.L.; Hale, B. Waste not, want not: The private and social costs of waste-to-energy production. Energy Policy 1997, 25, 587-600. [CrossRef]

14. Rabl, A.; Spadaro, J.V.; Mc Gavran, P.D. Health risk of air pollution from incineration: A perspective. Waste Manag. Res. 1998, 16, 365-388. [CrossRef]

15. Rabl, A.; Spadano, J.V. Health Impacts of Waste Incineration, Issues in Environmental Science and Technology. In Environmental Impact of Solid Waste Management Activities; Royal Society of Chemistry: London, UK, 2002; Volume 18, pp. $171-193$.

16. Gomez-Barea, A.; Leckner, B. Modeling of biomass gasification in fluidized bed. Prog. Energy Combust. Sci. 2010, 36, 444-509. [CrossRef]

17. Kaushal, P.; Abedi, J.; Mahinpey, N. A comprehensive mathematical model for biomass gasification in a bubbling fluidized bed reactor. Fuel 2010, 89, 3650-3661. [CrossRef]

18. Puig-Arnavat, M.; Carles, B.J.; Coronas, A. Review and analysis of biomass gasification models. Renew. Sustain. Energy Rev. 2010, 14, 2841-2851. [CrossRef]

19. Panepinto, D.; Genon, G. Solid waste and biomass gasification: Fundamental processes and numerical simulation. Chem. Eng. Trans. 2011, 24, 25-30.

20. Campoy, M.; Go 'mez-Barea, A.; Ollero, P.; Nilsson, S. Gasification of wastes in a pilot fluidized bed gasifier. Fuel Process. Technol. 2014, 121, 63-69. [CrossRef]

21. Arafat, H.A.; Jijakli, K. Modeling and comparative assessment of municipal solid waste gasification for energy production. Waste Manag. 2013, 33, 1704-1713. [CrossRef] [PubMed] 
22. Panepinto, D.; Zanetti, M.C. Municipal solid waste incineration plant: A multi-step approach to the evaluation of an energyrecovery configuration. Waste Manag. 2018, 73, 332-341. [CrossRef] [PubMed]

23. Ragoßnig, A.M.; Wartha, C.; Pomberger, R. Climate impact analysis of waste treatment scenarios-Thermal treatment of commercial and pretreated waste versus landfilling in Austria. Waste Manag. Res. 2009, 27, 914-921. [CrossRef] [PubMed]

24. Cossu, R.; Pivato, A. Leachate and biogas. In Proceedings of the Seminar "The Reclamation of Old Landfills", Padua, Italy, 10-12 June 2002.

25. Greater London Autorithy. Costs of Incineration and Non Incineration-Energy from Waste Technologies; Greater London Authority: London, UK, 2008.

26. Barni, E.; De Stefanis, P.; Iaboni, V.; ENEA (Agenzia Nazionale per le Nuove Tecnologie, L'energia e lo Sviluppo Economico Sostenibile). Evaluation of the Investment Cost for the Acerra Incineration (in Italian "Valutazione del Costo di Investimento del Termovalorizzatore di Acerra". 2010. Available online: https://www.researchgate.net/publication/265752738 (accessed on 31 January 2018).

27. Directive 2008/98/EC of the European Parliament and of the Council of 19 November 2008 on Waste and Repealing Certain Directives. Available online: http:/ / eur-lex.europa.eu/LexUriServ/LexUriServ.do?uri=OJ:L:2008:312:0003:0030:en:PDF (accessed on 30 April 2018). 